\title{
Delineating Ecosophy as a Counter Discourse in Barbara Kingsolver's Flight Behaviour
}

\author{
Anita Jose \\ Ph.D Research Scholar \\ Department of English \\ St.Aloysius College, Thrissur \\ University of Calicut \\ Kerala, India \\ annjose11@gmail.com
}

Dr. Betsy Paul C.

Associate Professor and Research Guide

Department of English

St.Aloysius College, Thrissur

University of Calicut

Kerala, India

betspaulc@gmail.com

\begin{abstract}
:
Flight Behaviour by Barbara Kingsolver is a clarion call aimed at exposing the impending future that awaits humanity in the form of grievous climactic changes and its impact on the delicate ecosystem of the earth. The characters presented who maintain varying perspectives regarding ecological concerns may be seen as representing differing ideologies that persist in the society with respect to the same. The paper is an attempt to trace the dominant as well as
\end{abstract}


alternate voices that pervade discussions on an apocalyptic future due to human actions that are ruthless and highly exploitative of ecological resources. The mystical encounter with nature that the protagonist undergoes will be examined to understand the significance of an ecological philosophy or "ecosophy." The paper would also seek to discern a transition from anthropocentrism to ecocentrism and also the disruption of nature/culture binaries established by an anthropocentric worldview depicted in the text.

Keywords: Flight Behaviour, Ecosophy, Anthropocentrism, Ecofeminism, Arne Naess

\section{Introduction:}

Apprehensions regarding an ecological apocalypse looms large over the world with efforts undertaken by environmentalists to eliminate the possibilities of such a scenario. When notions of human development and progress ensues from an anthropocentric stance which does not pay attention to ecological concerns, the repercussions are likely to be drastic. A knowledge system that acknowledges the inherent value of oikos (ecology), is deemed necessary to avert such impending dangers. In this context, the paper considers the notion of "ecosophy" or an "ecological philosophy" popularised by Arne Naess as a possible alternative that could replace the dominant discourses of the current era that privilege man over nature as presented in the novel Flight Behaviour by Barbara Kingsolver. It can be understood as positing various perspectives maintained by the characters that possess implications for an ecological and thereby human well-being. The paper intends to discern and examine these perspectives in detail within the purview of ecosophy.

Flight Behaviour depicts a scenario where "Monarch butterflies" who migrate to Mexico during winter changes their course to the Appalachians which is a highly unlikely choice as the latter can have freezing temperatures during winter that could kill the butterflies. Connecting this drastic change in destination to changes in climactic patterns that confuse the 
butterflies, Kingsolver implies that it could be an ominous sign signaling the serious repercussions that could ensue from climactic changes. She makes the Monarch butterflies (monarchs) or the "King Billies," as they are endearingly called by a few characters, the vantage point to engage in serious deliberations on the differing notions of such changes in weather pattern and the reception of the same by people in different sections of the society, specifically, the locals residing at Cleary, in the Appalachians, the scientists and the media who inhabit the universe of the novel. She seems to pit the concept of "ecosophy," as maintained by Dellarobia, the protagonist and Ovid Byron, the scientist who studies the "monarchs" against the dominant discourses of anthropocentrism and objectification of nature for monetary gains. The latter is evident in the "myth" of climate change that Dr. Byron mentions and the sole focus on romantic aspects of a natural phenomenon than the reality as presented by Tina Ultner, a media representative, who covers a feature on the monarchs.

2. Ruminations on Ecosophy:

The concept of "ecosophy" is associated with the Norwegian philosopher Arne Næss, who coined the term in a 1972 lecture. It may be deemed as a philosophy that considers the relationship between man and nature and that which upholds interconnection of both through an expanded "self-realisation." Naess' considerations regarding ecological philosophy shows that according to him, "the fundamental norm of ecosophy $\mathrm{T}$ is "self-realization." But not in any narrow, individualistic sense" (59) where "ecosophy T" is Naess' version of ecological philosophy and "T" here refers to "Tvergastein, the arctic mountain hut Næss commissioned while still in his twenties, and where he has dwelt seasonally for almost seventy years" thus showing how "the man and the mountain have been on intimate terms" for years (Cocola par. 11). Examining the idea of "self-realization" in the context of Naess' observations it may be understood as that which accommodates and values other selves in its fold thus evincing an expansion of a single, isolated, individual "Self." Such a conception encourages the notions of 
interconnectedness thus enabling the humans to realise the role of non-human elements as imperative for their survival. Essentially, it points to the deconstruction of nature/culture binaries, eliciting a renewed form of the self that is inclusive rather than exclusive.

Naess' explanation of such an ecological wisdom which is founded "on the distinction between Self and self ,conceived in certain Eastern traditions of atman; comprising all the life forms and selves (jivas) as usually interpreted in social and personal life" (59) also exhibits panentheistic underpinnings vested within the philosophy. 'Panentheism' foregrounds the presence of divine spark in animate and inanimate beings and the joy that ensues from this realisation. This idea upholds the immanence of God in the universe and also echoes the point of view of Indian cosmology which considers 'Prakriti' (nature) as the manifestation of "primordial dynamic energy" which is 'Shakti' (Shiva 37). Panentheism, thus serves to emphasise the unity and inter-connectedness of all forms of life and help forge an ecological consciousness. Such deliberations go hand in hand with the concerns of "deep ecology" that seek to value the inherent value and diversity of all natural forms and to arrest ruthless manipulation and exploitation of non-human life forms. A brief glance at the few of the basic tenets of deep ecology framed by Naess and George Sessions provides a better insight:

(1)The well-being and flourishing of human and non-human life on Earth have value in themselves. The values are independent of the usefulness of the nonhuman world for human purposes.

(2) Richness and diversity of life forms contribute to the realization of these values and are also values in themselves.

(3) Humans have no right to reduce this richness and diversity except to satisfy vital needs.

...(5) Present human interference with the non-human world is excessive and the situation is rapidly worsening. (49-50) 
Such perceptions vividly point to an immediate transition to be envisaged from anthropocentrism to ecocentrism especially at the wake of "the troubling awareness that we have reached the age... when the consequences of human actions are damaging the planet's basic life support system" (Glotfelty xx). Kingsolver in Flight Behaviour presents the migration of the monarchs to the Appalachians as the signal of an impending disaster that can be averted only via the inculcation of a wisdom that instills a pro-ecological mindset.

\section{Ecosophy in Flight Behaviour:}

The novel commences with Dellarobia's encounter with the Monarch butterflies which may be deemed as a mystical encounter with nature that awakens in her a renewed sense of self. It begins with an exploration outside the confines of her house though she undertakes such a journey with another purpose. The physical journey takes the form of an inward journey as she experiences a blurred vision of "the forest blazed with its own internal flame... every bough glowed with an orange blaze" which had actually been the Monarch butterflies as she later realises, "the fire was alive, and incomprehensibly immense, an unbounded, uncountable congregation of flame-coloured insects" (Kingsolver 19, 72). This experience which resembles Moses' encounter with God in the burning bush, becomes the juncture at which a near-mystical initiation is envisaged in her. The persona she embodies thereafter, largely exhibits ecological awareness and 'ecosophy' as she is able to comprehend the inherent worth of non-human lives and their significance in the larger scheme of things that ensure survival on earth.

Along the lines of Naess' conception of ecosophy which he deems to be "a "personal philosophy" that guides our conduct toward the environment," (Young and Smith) Dellarobia may be considered to be initiated into an ecological wisdom that triggers her to create a personal philosophy of her own which considers non-human lives to be at par with humans with respect to the former's behavior. During the act of sheep shearing her observation of the ewes encourages her to reflect on the composite yet intelligent nature of these animals, "watch and 
learn, Dellarobia thought... Today they struck her as crannier than the people...They would watch, ears up, forepaws planted, patiently bearing with the mess made by undisciplined humans as the world fell down around them (Kingsolver 34). Such reflections that deviate from an anthropocentric axis, are definitely a result of an awakened consciousness. It invariably comes with the understanding that the life force that works within everyone is the same and it is imperative to return to that self which is capable of blending with the ultimate consciousness through a seamless integration with the spirit of the natural world. This seamless integration also echoes an 'organic synthesis' that explains the unity of all forms of the dialectic and will enable us to emphasis the interrelated characteristics of all elements constituting the totality" (Varadachari 9). It arises from "the idea of nature as a living organism which has philosophical antecedents in the ancient systems of thought" (Merchant 10). Dellarobia's epistemological systems of thought though not based on scientific reasonings, works on an intuitive level and showcases how sacredness associated with natural elements could prove to encourage conservation.

Dr. Ovid Byron a scientist who functions purely at scientific terms too maintains an ecosophical attitude in trying to fathom a reason for the change in the migratory course of the butterflies which he ultimately traces to variations in climactic patterns. In attempting to present solid proof to the scientific community and the world at large he aims to prove that climate change is a reality and not merely a myth as many would want it to be considered: "A continental ecosystem is breaking down. Most likely, this is due to climate change. Really I can tell you I'm sure of that. Climate change has disrupted this system" (Kingsolver 325, 318). In encouraging Dellarobia to join in the scientific pursuits he acknowledges the experience and traditional knowledge of the local population in the restoration of the pristine ecological order. Through this action, he realises Vandana Shiva's words in Staying Alive, "it is not only as victims but also as leaders in creating new intellectual paradigms that women are central to 
arresting and overcoming ecological crises," especially while considering the fact that Dellarobia was trying to escape the limiting confines of her domestic life when she initially reached the woods (45).

Dr. Byron understands that it is imperative to tackle the issue at the grassroots level and is highly intolerant of the ignorance of a large population regarding the ecological crises that they are encountering across the globe. The serious repercussions that ensue from models of development that are highly aggressive and exploitative in effect lead to what Shiva terms 'maldevelopment' that creates an "ontology of dichotomisation" that "generates an ontology of domination, over nature and people. Epistemologically, it leads to reductionism and fragmentation" (40).

The tendency to overlook such drastic changes could have far-reaching implications including the total wipe out of humanity as Dellarobia realises, "Man against Nature. Of all the possible conflicts, that was the one that was hopeless. Even a slim education had taught her this much: Man loses" (Kingsolver 339). Even though, the less-educated Dellarobia is able to arrive at such a conclusion which clearly represents the ecological philosophy she has imbibed, Kingsolver presents yet another discourse that is seemingly endorsed by at least a good proportion of the scientific community and environmentalists regarding global warming and climate change and human contribution towards the same. Tina Ultner becomes the mouthpiece of this discourse who strongly argues, "Dr. Byron, let's talk about global warming. Scientists of course are in disagreement about whether this is happening, and whether humans have a role.... (Kingsolver 505-506). Byron vehemently opposes these propositions remarking that "Unseasonable temperature shifts, droughts, a loss of synchronization between foragers and their host plants. Everything hinges on the climate... Even the most recalcitrant climate scientists agree now, the place is heating up. Pretty much every one of the lot" (Kingsolver 504-505). 
The fear of an impending doom underlies these statements which can be averted only through proactive intervention. To counter such discourses that portray climate change as a myth, one needs to have assimilated an intricate pattern of relationship with the natural world in a way that any disturbance in the ecological surroundings would disturb individual minds as well. Dellarobia's and Ovid Byron's affinity with the environment arises from the realisation of such an indistinguishable bond that may be traced to the ecological wisdom or ecosophy they have garnered. They vividly represent individuals with an expanded "self-realisation" as Naess conceives as they are capable of acknowledging the inherent values of all life-forms and selves within the purview of two different systems in which they operate; Dellarobia as a nurturing mother bound to domestic responsibilities and Byron as a scientist pursuing research in his area of interest. But, both of them relate to their natural environment as a living organism which needs to be preserved with utmost care and this is why they are capable of going beyond the captive beauty of the monarch butterflies and fathom a reason unlike others who commercialise this beauty for monetary benefits.

Kingsolver foregrounds the tendency to commercialise natural beauty or romanticise it in order to gain monetary benefits in the persona of Tina Ultner who tries to improve viewership ratings. Also a few members of the Turnbow family as well as the state who try to exploit the tourism prospects of the region where the monarchs have migrated in large numbers also exhibit similar tendencies. The way how certain individuals and state officials "sell" the monarchs to improve tourism prospects become evident in the plans to develop an amusement park where the monarchs have migrated. Ovid Byron too rages at nature being objectified for its beauty and devoured for the monetary benefits that thus ensue when Tina emphasises just the beauty aspect of the monarchs overlooking the dangerous implications of their migration to Appalachians rather than to Mexico, their normal roosting site, "Tina. To see only beauty here is very superficial. Certainly in terms of news coverage, I would say it's off message" 
(Kingsolver 503). This sort of objectification has potential to divert attention from pressing ecological issues and Kingsolver reminds that it must be handled with caution.

4.Conclusion:

Kingsolver in Flight Behaviour not only presents the case for initiating an ecological wisdom but also derides the tendency to objectify nature. She rightly observes that ruthless human actions are currently posing a threat to the survival of all beings and there is a need to thwart it by acknowledging the diversity and richness of nature thus, exhorting the values promoted by deep ecological concerns. This attitude deviates from the ethos of anthropocentrism and discourages any attempt to romanticise nature for material consumption. Dellarobia and Ovid Byron represented as figures vocalising the apprehensions regarding climate change and global warming become mouthpieces exhorting a serious intervention at local and global level. They take efforts and endeavour to create an awareness invariably due to an ecological wisdom or 'ecosophy' they have assimilated in their selves. 


\section{Works Cited:}

Cocola, Jim. "Ecosophy from T to X.” April 2006.

https://nplusonemag.com/online-only/online-only/ecosophy-t-x. Accessed Jan. 2020.

Glotfelty, Cheryll and Harold Fromm. "Inroduction". Ecocriticism Reader: Landmarks in Literary Ecology. University of Georgia Press, 1996.

Kingsolver, Barbara. Flight Behaviour. Harper Collins Inc., 2012.

Merchant, Carolyn. "Nature as Female.” Ecocriticism: The Essential Reader, edited by Ken Hiltner. Routledge, 2015.

Naess, Arne. "The Deep Ecological Movement: Some Philosophical Aspects.” Ecocriticism:

The Essential Reader, edited by Ken Hiltner. Routledge, 2015.

Shiva, Vandana. "Women in Nature." Staying Alive. Kali for Women, 1988.

Varadachari, K.C. "Vishishtadvaita: A synthesis of philosophy and Religion".

Vishishtadvaita and its Development. Chakravarty Publications, 1969.

Young, Gerald L and Douglas Smith. "Ecosophy.” ENCYCLOpedia.com. Dec. 2019. https://www.encyclopedia.com/environment/encyclopedias-almanacs-transcripts-andmaps/ecosophy. Accessed Jan. 2020. 